\title{
Outpatient laparoscopic cholecystectomy. A new gold standard for cholecystectomy?
}

\author{
J. Bueno Lledó, M. Planells Roig, C. Arnau Bertomeuํ, A. Sanahuja Santafé, M. Oviedo Bravo, R. García \\ Espinosa, R. Martí Obiol and A. Espí Salinas
}

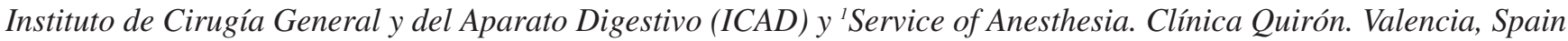

\begin{abstract}
Objective: to contribute our experience for five years in the implemetation of outpatient laparoscopic cholecystectomy (LC).

Patients: between January 1999 and March 2004 we performed 504 outpatient LCs. We applied both exclusion and inclusion criteria, an anesthetic and surgical protocol, and discharge-specific criteria. Postoperative management in "fast track" regime. Postoperative period controlled by protocol, including phone calls after cholecystectomy.

Results: the ambulatory percentage in the global series was $88.8 \%$, and mean hospital stay was 6.1 hours. Fifty-one patients required overnight stays $(10.1 \%)$, most of them for "social" causes. Five patients required admission (between 24 and 48 hours) for different causes (conversion to laparotomy, intraoperative neumothorax, and postoperative medical complications). Six patients (1.1\%) were readmitted, and we observed $11.6 \%$ postoperative complications in the global series, with abdominal parietal pain being most frequent. Phone localization by 22.00 p.m. in the same day of surgery was $100 \%$ complete for outpatient cases. Postoperative surveillance within the first month after surgery was completed in $93.9 \%$, and within th first year in $86.7 \%$ of patients.

Conclusions: outpatient LC is safe and feasible, and probably represents a new "gold standard" in the treatment of symptomatic cholelithiasis.
\end{abstract}

Key words: Cholelithiasis. Laparoscopic cholecystectomy. Outpatient surgery.

Bueno J, Planells M, Arnau C, Sanahuja A, Oviedo M, García Espinosa R, Martí R, Espí A. Outpatient laparoscopic cholecystectomy. A new gold standard for cholecystectomy? Rev Esp Enferm Dig 2006; 98: 14-24.

Recibido: 20-04-05.

Aceptado: 06-09-05.

Correspondencia: Manuel Planells Roig. Instituto de Cirugía General y del Aparato Digestivo (ICAD). Clínica Quirón. Avda. Blasco Ibáñez, 14. 46010 Valencia. Fax: 9639317 06. e-mail: mplanells@bsab.com

\section{INTRODUCTION}

The postoperative benefits of patients after laparoscopic cholecystectomy (LC) versus the traditional open approach has led this surgery to spread among the surgical community with prompt acceptance (1). Reduced postoperative time allows early mobility and a rapid restart of oral tolerance. On the other hand, the intraoperative time of LC has been diminishing progressively, and is shorter in simple cases than that of traditional surgery. These characteristics allow most LCs to be performed in "shortstay surgery" conditions, with 24-48-hour admissions (2).

Reddick and Olsen contributed the concept of ambulatory LC in 1990 (3). In our country several groups have been pioneers in this type of surgery (4-6). Nevertheless, LC has been accepted as an outpatient procedure not even in Europe, due to the role that some authors attribute to the late detection of postoperative complications from cholecystectomy.

The aim of our study was to contribute our experience in the development and implementation of a series of 504 $\mathrm{LC}$ for five years in an ambulatory surgery program.

\section{MATERIAL AND METHODS}

We analyzed 504 LCs for symptomatic cholelithiasis performed between January 1999 and March 2004 in Instituto de Cirugía y Aparato Digestivo (ICAD) of Clínica Quirón in Valencia, Spain. Some patients were excluded from the study after their anesthetic classification as unstable ASA III or ASA IV patients with acute cholecystitis, and with direct or indirect signs of choledocolithiasis. Selection criteria for ambulatory LC included stable ASA I, II or III, absence of anesthetic complications in previous surgeries, presence of a competent adult in the home for the initial 24 hours or placement at less than $100 \mathrm{~km}$ away from hospital. An informed specific, anest- 
hetic and surgical consent was obtained for the procedure in all cases.

All the procedures were programmed in the morning, and admissions occurred one hour before the operation. The anesthetic team was always the same. The anesthetic procedure was protocolized. We tried to minimize the use of opiates during the anesthetic procedure. Cholecystectomy was performed according to the "European" technique, with a pre- and post-procedural subphrenic and subhepatic irrigation, including the hepatic bed and Calot's triangle, with a solution of $0.5 \%$ bupivacaine. No intraoperative cholangiogram (IC) was performed.

Postoperative management in a "fast-track" regimen has been previously published (6). Hospital discharge was decided by the surgical unit on the basis of the following criteria: stable vital signs, controllable pain with oral analgesia, no vomiting, absence of bleeding at trocar wounds, tolerance to liquids, and independent ambulation.

"Outpatient" was defined as a hospital stay for less than 8 hours. Hospital stay was defined as the time from anesthetic induction completion to definitive discharge. Overnight patients were considered those who remained in hospital for 8 to 23 hours. Admission defined patients with a stay longer than 24 hours. Readmission defined patients who needed admission after hospital discharge.

Admission criteria included difficult surgical technique, unstable vital signs, difficult-to-control pain with oral analgesics, uncontrolled nausea or vomiting $(\mathrm{N} / \mathrm{V})$, or a "social cause" due to patient refusal or preference in spite of preoperative information. Outpatients received postoperative written instructions with general information about postoperative care, and a series of "alert" signs or symptoms (excessive abdominal pain, wound bleeding, repeat vomiting) that should prompt immediate phone contact with the hospital. Phone contact with the surgeon was routine and mandatory at $22.00 \mathrm{p} . \mathrm{m}$. on the procedure day, to report on the patient's postoperative status.

Besides this phone contact, postoperative follow-up continued to the third postoperative day ( 72 hours) and then at week 1 , day 14, month 1 , month 3 , month 6 and 1 year after the procedure. The statistical analysis was performed using a commercial software package (SPSS, version 12.0). Constant variables were confirmed by means of the Student's t test, with statistical significance in $p$ $<0.05$. Dichotomic variables were analyzed by means of the Chi-squared test and Fisher's test, when necessary.

\section{RESULTS}

From January 1999 to March 2004, 504 consecutive LCs were performed. The demographic and clinical characteristics of patients are shown in table I. Average duration of general anesthesia was $68.6 \pm 24.3$ minutes. Surgery average duration was $46.4 \pm 14.5$ minutes $(45 \pm 22.4$ minutes in strictly ambulatory ones). Of 504 consecutive patients, only 448 were outpatient cases, which repre-
Table I. Demographics and clinical findings

\begin{tabular}{|c|c|c|}
\hline & Outpatient (\%) & $\begin{array}{c}\text { Non } \\
\text { outpatient (\%) }\end{array}$ \\
\hline $\begin{array}{l}\text { Gender } \\
\text { Male } \\
\text { Female }\end{array}$ & $\begin{array}{l}110(24.6) \\
338(75.4)\end{array}$ & $\begin{array}{l}19(33.9) \\
37(66.1)\end{array}$ \\
\hline $\begin{array}{l}\text { Obesity } \\
\text { Thin }(\text { BMI < 20) } \\
\text { Normal }(\text { BMI: } 20-25) \\
\text { Obese }(\text { BMI > 25) }\end{array}$ & $\begin{array}{r}23(5.1) \\
217(48.4) \\
204(46.4)\end{array}$ & $\begin{array}{r}3(5.4) \\
22(39.3) \\
31(55.3)\end{array}$ \\
\hline $\begin{array}{l}\text { ASA } \\
\text { I } \\
\text { II } \\
\text { II stable }\end{array}$ & $\begin{array}{r}252(56.3) \\
183(40.8) \\
13(2.9)\end{array}$ & $\begin{array}{r}29(51.8) \\
21(37.5) \\
6(10.7)\end{array}$ \\
\hline $\begin{array}{l}\text { POSSUM } \\
20-21 \\
22-23 \\
24-25\end{array}$ & $\begin{array}{r}197(44) \\
222(49.6) \\
29(6.5)\end{array}$ & $\begin{array}{r}25(44.6) \\
23(41.1) \\
8(14.3)\end{array}$ \\
\hline $\begin{array}{l}\text { Age } \\
\text { Median (SD) }\end{array}$ & $53.1(14.5)$ & $57.54(14.1)$ \\
\hline $\begin{array}{l}\text { History } \\
\text { Biliary dyspepsia } \\
\text { Biliary acute event } \\
\text { Acute cholecystitis } \\
\text { Biliary pancreatitis } \\
\text { Jaundice }\end{array}$ & $\begin{array}{r}89(19.9) \\
306(68.3) \\
24(5.4) \\
22(4.9) \\
7(1.6)\end{array}$ & $\begin{array}{r}7(12.5) \\
35(62.5) \\
7(12.5) \\
5(8.9) \\
2(3.6)\end{array}$ \\
\hline $\begin{array}{l}\text { Preoperative clinical sta } \\
\text { Non-symptomatic } \\
\text { Biliary dyspepsia } \\
\text { Biliary acute episode }\end{array}$ & $\begin{array}{r}94(21) \\
304(67.8) \\
50(11.2)\end{array}$ & $\begin{array}{r}5(8.9) \\
12(21.4) \\
39(69.7)\end{array}$ \\
\hline
\end{tabular}

SD: standard deviation.

sents $88.8 \%$ of the total amount in the series, with average hospital stay in this group being $6.1 \pm 1.2$ hours. On the contrary, 51 patients needed an overnight stay, which represents $10.12 \%$ of cases, with hospital stays shorter than 24 hours. The majority of these patients were admitted to Hospital for "social" reasons (refusal of patient or relatives) or because the intervention had finished after 5 p.m., which is an unacceptable time for discharge from a medical and social point of view (Table II).

The temporary evolution of the series and the learning curve of the surgical unit are shown in table III.

The mandatory telephonic contact at 22.00 hours on the same day of surgery was fulfilled in $100 \%$ of cases. Of them, 410 patients did not present any alert symptoms. Thirty-three patients developed abdominal pain: oral analgesia and a new consultation were prescribed in case of pain persistence, none of them needing readmission. Thirteen patients had N/V, and they took metochlopramide orally in eleven cases, and ondansetron in the remaining ones, with no need for admission. Eleven patients $(2.1 \%)$ were lost to follow-up, as they did not go back to hospital after their first two postoperative controls (72 hours and 1 week). Postoperative follow-up to 1 month after the procedure was $93.9 \%$, and to 1 year 
Table II. Causes of overnight stay, admission, and readmission after LC

\begin{tabular}{lcc}
\hline & $\mathbf{N}^{\mathbf{0}}$ & Treatment \\
\hline Overnight admission (10.1\%) & & \\
Refusal of patient or relatives (social cause) & 18 & \\
Conclusion of surgery after 5.00 p.m. & 9 & \\
Extended curarization & 2 & \\
Acute respiratory failure & 4 & Symptomatic therapy \\
Help needed for ambulation & 2 & \\
Postoperative pain & 1 & \\
Umbilical wound hematoma & 1 & Symptomatic therapy \\
Vomiting & 6 & Ondansetron \\
Technical complexity of surgery & 6 & \\
Thoracic pain & 1 & \\
Uncontrolled hyperglycemia & 1 & \\
Admission (0.99\%) & & \\
Conversion to open procedure & 2 & \\
Congestive cardiac failure & 1 & \\
Schizophrenic psychosis & 1 & Psycotropal medication \\
Intraoperative pneumothorax & 1 & Thoracic drainage \\
Readmission (1.2\%) & & \\
Vomiting & 2 & Symptomatic therapy \\
Subphrenic collection & 1 & Conservative \\
Acute biliary pancreatitis & 1 & Conservative \\
Subhepatic collection & 1 & Conservative \\
Postoperative intestinal obstruction & 1 & Surgery \\
\hline ICU: & & \\
\hline
\end{tabular}

ICU: intesive care unit.

was $86.7 \%$ of patients (Table IV). There were 4 conversions $(0.7 \%)$ in the global series, caused by 2 cases of dense adherences with inability to recognize structures, 1 patient with a mass between the gallbladder and stomach, and a shrunken gallbladder, and finally loss of the gallbladder inside the abdomen after cholecystectomy.

Five patients needed readmission (between 24 and 48 hours) for different reasons, including: a) conversion to open surgery (2 cases); b) intraoperative pneumothorax from injury in the diaphragmatic suprahepatic area; and c) medical postoperative complications (cardiac insufficiency and psychosis). Two intraoperative complications arouse: intestinal injury during manipulation with a dissector, solved with intracorporeal suture with reabsorbable material, and a case of diaphragmatic suprahepatic perforation that was treated conservatively using thoracic drainage. Sixty-three postoperative complications were observed (11.6\%) in the global series, and parietal abdominal pain was the most frequent. The percentage of complications in the initially ambulatory patients was $10.9 \%$. Six patients were readmitted in our hospital: two of them for repeat vomiting episodes managed with symptomatic treatment; the other patient for acute biliary pancreatitis, which was solved with conservative therapy;
Table III. Ambulatorization percentage and outcome

\begin{tabular}{lrrrr}
\hline & Outpatient & Overnight & Admission & Global \\
\hline 1999 & $41(70.1 \%)$ & 14 & 3 & 58 \\
2000 & $72(92.3 \%)$ & $5(6.4 \%)$ & $1(1.2 \%)$ & 78 \\
2001 & $95(88.8 \%)$ & $12(11.2 \%)$ & 0 & 107 \\
2002 & $98(90.7 \%)$ & $9(8.3 \%)$ & $1(0.9 \%)$ & 108 \\
2003 & $114(91.9 \%)$ & $10(8.1 \%)$ & 0 & 124 \\
$2004 *$ & $28(96.5 \%)$ & $1(3.5 \%)$ & 0 & 29 \\
GLOBAL & 448 & 51 & 5 & 504 \\
\hline
\end{tabular}

*Period until March 2004

Table IV. Postoperative follow-up of patients according to control periods

\begin{tabular}{lc}
\hline \multicolumn{1}{c}{ Postoperative controls } & Percentage of follow-up \\
\hline Phone contact (22.00 h p.m.)* & $448(100 \%)$ \\
In $72 \mathrm{~h}$ & $501(99.4 \%)^{* *}$ \\
In 7 days & $503(99.8 \%)$ \\
In 14 days & $493(97.8 \%)$ \\
In first month & $473(93.9 \%)$ \\
In 3 months & $462(91.6 \%)$ \\
In 6 months & $454(90.0 \%)$ \\
In first year & $437(86.7 \%)$ \\
\hline
\end{tabular}

*strictly ambulatory patients.

**three admitted patients did not come for proximity of discharge.

a patient with a subphrenic collection manifesting with fever and abdominal right-area pain was also managed with intravenous antibiotic treatment; the last one developed generalized abdominal pain at 72 hours after surgery, and a subhepatic collection plus intraabdominal fluid were found, which needed no surgery, only conservative treatment and close surveillance for 5 days. A sixth patient was readmitted to another institution because of an intestinal obstruction episode that needed surgical treatment after one week due to an adherencial syndrome (Table II).

\section{DISCUSSION}

The advent and development of surgery in "fast track" regimens (7) and the manipulation of factors influencing postoperative immediate recovery (anesthetic technique poor in opiates, administration of NSAIDs, anti-emetic prevention, and multimodal analgesia) have allowed the possibility of developing and implementing an "ambulatorization" in several surgical processes where this had been previously impossible. Several authors have demonstrated the usefulness of local anesthetic instillation 
(especially bupivacaine) before the laparoscopic incision, thus contributing to the minor component of postoperative pain, the need of lower doses of analgesia, and a more rapid recovery to daily activity versus patients not receiving it or having it administered after the surgical incision (8-11).

Anti-emetic prevention, the utilization of propofol as a rapid anesthetic inductor with minimal undesirable residual effects, and the association during anesthetic induction of NSAIDs (ketorolac) have all permitted a successful ambulatorization of LC $(6,13,14)$, which is according to various series around 55-97\% (12-15). Table V shows series reported along the development of the outpatient approach, including case numbers and ambulatorization percentage (15-33).

A crucial aspect in the development of the ambulatory surgery program is the criteria for patient selection. The rate of unexpected admissions in ambulatory LC is a quality index, as it might represent the existence of inadequate criteria in the selection of patients who given their characteristics, precedents, or preoperative findings were not candidates to this type of surgery. This percentage in the analyzed series is around $1-39 \%$, mainly due to postoperative symptoms (vomiting and abdominal pain), the elective conversion to open surgery, and patient insecurity (13). Some authors have come to the conclusion that patients most likely to fulfill the criteria of outpatient LC are those who have an anesthetic preoperative classification of ASA I or II, with no previous abdominal surgery, no history of acute cholecystitis episodes, and a procedure duration shorter than 90 minutes $(3,14,16)$.

A number of factors preclude ambulatory LC, including delayed detection of potential postoperative complications, discharge acceptance by the patient, or development of undesirable postoperative symptoms (N/V, abdominal postoperative pain).

Diverse authors question the safety of ambulatorization arguing the potential for delayed detection, and therefore solution, of postoperative complications that cannot be demonstrated within 24 hours after surgery $(14,17)$. The main reticence regarding the ambulatory approach derives from the fact that many surgeons prefer periods of at least 24 hours with overnight stay, which avoid delays in the detection of some complications in the immediate postoperative period. On the contrary, other authors argue that the incidence of a life-threatening complication, including arterial bleeding, is very low (1/2000), and as such is symptomatic within hours during the postoperative period, thus being possibly detected while the patient is still in hospital (18).

A complication such as biliary iatrogenics develops in LC between 0.30 and $1 \%$ of cases (19). If not detected intraoperatively, secondary symptoms develop, including a biliary collection (abdominal pain, fever, etc.), or jaundice during the postoperative period. These complications cannot be detected before the second postoperative day (18). In our case, we present a patient with a subphrenic
Table V. Studies related with ambulatory LC and porcentage of ambulatorization failure

\begin{tabular}{lrrr}
\hline \multicolumn{1}{c}{ Centro } & Año & Patients & $\begin{array}{r}\text { Fracaso } \\
\text { ambulatory \% }\end{array}$ \\
\hline Redck et al. (3) & & & 53 \\
Arregui et al. (1) & 1990 & 106 & 1 \\
Stephenson et al. (18) & 1993 & 15 & 20 \\
Smith et al. (19) & 1994 & 266 & 19 \\
Saunders et al. (15) & 1995 & 506 & 32 \\
Prasad et al. (20) & 1996 & 103 & 8 \\
Fiorillo et al. (17) & 1996 & 149 & 39 \\
Taylor et al. (16) & 1996 & 108 & 32 \\
Lam et al. (21) & 1997 & 213 & 2.8 \\
Mjaland et al. (10) & 1997 & 200 & 6 \\
Narain et al. (22) & 1997 & 60 & 3 \\
Voitk et al. (23) & 1997 & 273 & 5 \\
Keulemans et al. (7) & 1998 & 37 & 8 \\
Hollington et al. (24) & 1999 & 60 & 18.3 \\
Fleisher et al. (36) & 1999 & 130 & 6.2 \\
Critchlow et al. (25) & 1999 & 60 & 45 \\
Fleming et al. (26) & 2000 & 45 & 17.7 \\
Win Tai Siu et al. (27) & 2001 & 60 & 10 \\
Calland et al. (28) & 2001 & 177 & 28 \\
Bringman et al. (29) & 2001 & 100 & 11 \\
Richardson et al. (13) & 2001 & 847 & 25.5 \\
Serralta et al. (6) & 2001 & 271 & 28.8 \\
Lau et al. (14) & 2002 & 888 & 3.2 \\
Curet et al. (30) & 2002 & 80 & 10.8 \\
Johanet et al. (31) & 2002 & 100 & 17 \\
Bal et al. (32) & 2003 & 383 & 7 \\
Leeder et al. (33) & 2004 & 154 & 14.3 \\
\hline & & & \\
\hline
\end{tabular}

collection that was detected with fever and pain in the right hypochondrium the fourth postoperative day, and which solved with endovenous antibiotic treatment with no need for percutaneous therapy. Another patient presented to our hospital with generalized abdominal pain at 72 hours after LC, and a subhepatic collection plus free intraabdominal liquid was found in an ultrasound scan, which only needed conservative treatment for 5 days.

Likewise, in our case, the exclusion criteria for acute cholecystitis contributed to reduce cases with likely biliary injury. Therefore, a period of prudent observation for 4-6 hours may suffice, due to the fact that an overnight stay would not reduce the detection of subsequent major complications.

Individualization is essential for the preoperative management of ambulatory LC. The breaking of the cultural, habitual schedule of a surgical procedure requires strong collaboration between anesthetic and surgical teams, which eliminates the previous prejudices of the pa- 
tient at the time of accepting this change, in contrast to his cultural pre-established concept.

Therefore, suitable preoperative information is vital for the patient's acceptance of ambulatorization in order to diminish anxiety, facilitate recovery, and diminish hospital stay (20). In fact, acceptance before the ambulatory procedure shows differences among the various degrees of information demanded according to patient age, sex, education. Such information must assure home self-management during the postoperative period, and be exhaustive in order to ensure maximal quality of care, thus avoiding the undesirable effects of surgery "without information", which originates a high percentage of complications that remain undetected by the surgical unit $(21,22)$.

Eighteen patients were "overnight stay" cases due to "social causes". In spite of preoperative information protocols, according to which we discussed the surgical indication, management of the laparoscopic approach, possible complications (informed consent) and alert signs, comfortable postoperative period of LC, and achievements of ambulatory surgery, more than one third of patients preferred overnight stay. Therefore, strict postoperative control by the same surgical unit, and telephonic contact reinforce patient confidence, which is expressed in high percentage of postoperative follow-up (Table IV).

Finally, the learning curve for the technique also represents an important factor in the management of ambulatory LC (23). It is strictly necessary that this surgical technique is performed by expert surgeons with huge experience and involvement in laparoscopic management.

In conclusion, we think that outpatient LC is safe and feasible for the patient, and may probably represent a better-quality process and the "gold standard" technique for cholecystectomy.

\section{REFERENCES}

1. Arregui ME, Davis CJ, Arkush A, Nagan RF. In selected patients outpatient laparoscopic cholecystectomy is safe and significantly reduces hospitalization charges. Surg Laparosc Endosc 1991; 1: 240-5.

2. Martínez Ramos C, Sanz López R, Cabezón Gil, Cerdán Carbonero M. Ambulatorización de la colecistectomía laparoscópica. Cir May Amb 2004; 9: 13-8.

3. Reddick EJ, Olsen DO. Outpatient laparoscopic laser cholecystectomy. Am J Surg 1990; 160: 485-7.

4. Martínez A, Docobo F, Mena J, Durán I, Vázquez J, López F, et al. Colecistectomía laparoscópica en el tratamiento de la litiasis biliar: ¿cirugía mayor ambulatoria o corta estancia? Rev Esp Enferm Dig 2004; 96: 452-9.

5. Bermudez I, López S, Sanmillán A, González C, Baamonde de la Torre I, Rodríguez A, et al. Colecistectomía laparoscópica en régimen ambulatorio. Cir Esp 2004; 76: 159-63.

6. Serralta A, García Espinosa R, Martínez Casañ P, Hoyas L, Planells M. Cuatro años de experiencia en colecistectomía laparoscópica ambulatoria. Rev Esp Enferm Dig 2001; 93: 207-10.

7. Joshi GP, Twersky R. Fast tracking in ambulatory surgery. Amb Surg 2000; 8: 185-90.

8. Alexander D, Ngoi S, Lee L, So J, Mak K, Chan S, et al. Randomized trial of periportal peritoneal bupivacaine for pain relief after laparoscopic cholecystectomy. Br J Surg 1996; 83: 1223-5.

9. Maestroni U, Sortini D, Devito C, Pour F, Anania G, Pavanelli L, et al. A new method of preemptive analgesia in laparoscopic cholecystectomy. Surg Endosc 2002; 16: 1336-40.

10. Pasqualucci A, de Angelis V, Contardo R, Colo F, Terrosu G, Donini $A$, et al. Preemptive analgesia: intraperitoneal local anesthetic in laparoscopic cholecystectomy. A randomized, double-blind, placebo-controlled study. Anesthesiology 1996; 85: 11-20.

11. Bisgaard T, Klarskov B, Kristiansen VB, Callesen T, Schulze S, Kehlet $\mathrm{H}$, et al. Multi-regional local anesthesic infiltration during laparoscopic cholecystectomy in patients receiving prophylactic multi-modal analgesia. Randomized, double-blinded, placebo-controlled study. Anesth Analg 1999; 89: 1017-24.

12. Richardson W, Fuhrman G, Burch E, Bolton J, Bowen J. Outpatient laparoscopic cholecystectomy. Outcomes of 847 planned procedures. Surg Endosc 2001; 15: 193-5.

13. Lau H, Brooks D. Predictive factors for unanticipated admissions after ambulatory laparoscopic cholecystectomy. Arch Surg 2001; 136: 1150-3.

14. Saunders C, Leary B, Wolfe B. Is outpatient laparoscopic cholecystectomy wise? Surg Endosc 1995; 9: 1263-8.

15. Fiorillo M, Davidson P, Fiorillo M, D’Anna J, Sithian N, Silich R. 149 ambulatory laparoscopic cholecystectomies. Surg Endosc 1996; 10: 52-6.

16. Voyles CR, Berch BR. Selection criteria for laparoscopic cholecystectomy in an ambulatory care setting. Surg Endosc 1997; 11: 1145-6.

17. Llorente J. Laparoscopic cholecystectomy in the ambulatory surgery setting. J Laparoendosc Surg 1992; 2: 23-6.

18. Deziel D, Millikan K, Economou S, Doolas A, Ko S, Airan M. Complications of laparoscopic cholecystectomy: a national survey of 4,292 hospitals and an analysis of 77,604 cases. Am J Surg 1993; 165: 9-14.

19. Richardson M, Bell G, Fullarton G. Incidence and nature of bile duct injuries following laparoscopic cholecystectomy: an audit of 5913 cases. West of Scotland Laparoscopic Cholecystectomy Audit Group. Br J Surg 1996; 83: 1356-60.

20. Devine E. Effects of psychoeducational care for adult surgical patient's: A metaanalysis of 191 studies. Patient Education and Counseling 1990; 19: 129-42.

21. Planells M, Bueno J, Sanahuja A, García Espinosa R. Quality of life (GIQLI) and laparoscopic cholecystectomy usefulness in patients with gallbladder dysfuction or chronic non-lithiasis biliary pain (chronic acalculous cholecystitis). Rev Esp Enferm Dig 2004; 96: 442-51.

22. Landa JL. Buena cirugía es buena economía. Rev Esp Enferm Dig 2001; 93: 201-3.

23. Serralta A, Planells M, Bueno J, Sanahuja A, Espinosa R, Bertomeu $\mathrm{C}$, et al. The learning curve in ambulatory laparoscopic cholecystectomy. Surg Laparosc Endosc Percutan Tech 2002; 12: 320-4. 